\title{
Anti-Sporothrix brasiliensis activity of different pyrazinoic acid prodrugs: a repurposing evaluation
}

\author{
Stefanie Bressan Waller $^{1 *}$, Ceres Nakasu², Anna Luiza Silva ${ }^{1}$, Renata Osório de Faria ${ }^{1}$, \\ João Paulo dos Santos Fernandes ${ }^{3}$, Marlete Brum Cleff ${ }^{2}$
}

\begin{abstract}
${ }^{1}$ Centro de Diagnóstico e Pesquisa em Micologia Veterinária, Departamento de Veterinária Preventiva, Faculdade de Veterinária, Universidade Federal de Pelotas, Pelotas/RS, Brasil, ${ }^{2}$ Departamento de Clínicas Veterinárias, Faculdade de Veterinária, Universidade Federal de Pelotas, Pelotas/RS, Brasil, ${ }^{3}$ Departamento de Ciências Farmacêuticas, Universidade Federal de São Paulo, Diadema/SP, Brasil
\end{abstract}

\begin{abstract}
From drug repurposing studies, this work aimed to evaluate the activity of different pyrazinoic acid (POA) derivatives against Sporothrix brasiliensis. The POA esters were prepared and characterized as previously reported by classical esterification reactions, with good to excellent yields. Sporothrix brasiliensis isolates from cats $(n=6)$ and standard strains of $S$. brasiliensis and $S$. schenckii were used to assess the antifungal activity of the POA derivatives through broth microdilution assay (CLSI M38-A2). Among the tested compounds, molecules $\mathbf{3}$ and $\mathbf{4}$ showed fungistatic and fungicidal activities against all Sporothrix spp. strains, and the obtained MIC and MFC values ranged from 2.12 to $4.24 \mathrm{mg} / \mathrm{mL}$ and from 1.29 to $5.15 \mathrm{mg} / \mathrm{mL}$, respectively. Compound $\mathbf{2}$ and $\mathbf{5}$ were active as in vitro inhibitors of fungal growth, but showed weak fungicidal activity, while molecules $\mathbf{1}$ and POA itself were inactive. The results suggest the activity of POA derivatives against Sporothrix spp. may be dependent on the lipophilicity. In addition, the antifungal susceptibility of the isolates to itraconazole was performed, showing that two Sporothrix isolates from cats were itraconazole-resistant. Compounds $\mathbf{3}$ and $\mathbf{4}$ were also active against these itraconazole-resistant isolates, indicating a possible alternative route to the standard mode of action of itraconazole.
\end{abstract}

Keywords: Sporotrichosis. Sporothrix schenckii complex. Itraconazole. Antifungal resistance. Prodrugs. Pyrazinoic acid derivatives.

\section{INTRODUCTION}

Among the zoonotic diseases with importance in human and veterinary medicine, sporotrichosis should be highlighted due to the increasing reports in both human and animals. This infection is clinically characterized by subcutaneous nodules, ulcers and crusts, which can spread to systemic organs (Madrid et al., 2012). This mycosis is caused by agents of Sporothrix schenckii complex (Marimon et al., 2007) through the cutaneous inoculation by contaminated plant material (De Araújo et al., 2015) or by bite and scratch of animals, especially sick cats (Madrid et al., 2012; Montenegro et al., 2014; Rodrigues

\footnotetext{
*Correspondence: S. B. Waller. Centro de Diagnóstico e Pesquisa em Micologia Veterinária (MicVet), Departamento de Veterinária Preventiva, Faculdade de Veterinária, Universidade Federal de Pelotas (UFPEL). Rua Campus Universitário Capão do Leão, s/nº, Prédio 1, 96010-900, Pelotas/RS, Brasil. Phone +55 533275 7140. E-mail: waller.stefanie@yahoo.com.br
}

et al., 2014a). In Brazil, S. brasiliensis is prevalent in feline outbreaks and is considered one of the most virulent species (Montenegro et al., 2014; Rodrigues et al., 2014a).

Recently, the emergence of antifungal resistance has made the therapeutic control of the disease in animals more difficult (Rodrigues et al., 2014a; Borba-Santos et al., 2015; Waller et al., 2016), and has encouraged the search for new molecules with antifungal potential. With this regard, drug repurposing (or also called repositioning) is an approach that is frequently under consideration to find novel therapeutic options to diseases in the urgent state. The drug repurposing approach is based on study known drugs that are already approved for some disease or condition to treat another. Classical drug discovery and development pipeline is a slow and expensive process to find a new chemical entity (NCE), which includes the clinical trials, registry and several other processes to reach the patients. A large number of these NCEs never reach the 
clinical trials, and some other does not get the approval after that (Corsello et al., 2017).

In this panorama, repositioning is advantageous since the data from the NCE is already available from the approved drug. This is the main reason why this approach can speed up the translation of the active agent from the bench to the patient (Ashburn, Thor, 2004). The most famous example of successful repositioning of a drug is certainly the discovery of sildenafil (Viagra) to erectile dysfunction, which was before evaluated as a cardiovascular agent.

Pyrazinoic acid (POA) is a widely known antimycobacterial agent. It is proposed that POA is the active form of pyrazinamide (PZA), a first-class antimycobacterial drug used in human tuberculosis (Figure 1). The mechanism of action of both PZA and POA is not totally understood, but it depends firstly on the activation of PZA by a pyrazinamidase (PZAse) (Zhang et al., 2003). PZA also demonstrated to inhibit the fatty acid synthase I (FASI) in the NADPH binding site by competition (Zimhony et al., 2000). POA itself shows poor antimycobacterial activity due to its poor penetration into mycobacteria, and thus POA esters with better penetration were reported as options to circumvent this issue.

POA esters have shown good antimycobacterial activity in vitro against PZA-sensitive and resistant strains of Mycobacterium tuberculosis (Fernandes et al., 2014; Segretti et al., 2016). Furthermore, a repurposing study for PZA against Leishmania was reported (Mendez et al., 2009), showing the potential of these antimycobacterial compounds in affect other microorganisms, such as Leishmania major. However, none repurposing studies to POA derivatives were reported to date. Considering the repurposing strategy, the urgency of a novel therapeutic to sporotrichosis and the absence of literature information regarding the activity of POA derivatives against fungi, the aim of this study was to evaluate the activity of different POA derivatives against Sporothrix brasiliensis.

\section{MATERIAL AND METHODS}

\section{Material}

Chemical reagents for the preparation of the compounds were purchased from commercial sources in an adequate purity and used without prior treatment. ${ }^{1} \mathrm{H}$ and ${ }^{13} \mathrm{C}$ NMR spectra were recorded in a Bruker Ultrashield 300 spectrometer, operating at $300 \mathrm{MHz}$ and $75 \mathrm{MHz}$, respectively, using $\mathrm{CDCl}_{3}$ as a solvent with tetramethylsilane (TMS) as an internal standard. Chemical shifts are reported in parts per million (ppm, $\delta$ units). Coupling constants $(J)$ are reported in units of hertz $(\mathrm{Hz})$, if applicable. The NMR data is in accordance with previous reports in the literature. Culture medium of Potato-dextrose agar and Sabouraud dextrose-agar (Kasvi, Liofilchem ${ }^{\circledR}$, Italy) were used for fungal growth. For antifungal testing, the RPMI-1640 (Roswell Park Memorial Institute, Gibco ${ }^{\circledR}$, Life Technologies Co., United States) was prepared as liquid medium with addition of MOPS [3-(N-morpholino propanesulfonic acid)] (Alamar Tecno-Científica Ltda, Brazil), and itraconazole was purchased from pharmaceutical industry (Sporanox ${ }^{\circledR}$, Janssen-Pharmaceutica Ltda, Belgium).

\section{Preparation of the molecules $1-4$}

In a round-bottom flask, $5 \mathrm{mmol}$ of POA $(0.620 \mathrm{~g})$ were dissolved in $10 \mathrm{~mL}$ of appropriate alcohol (methanol, ethanol, butanol or 2-chloroethanol for compounds 1-4, respectively), and $7 \mathrm{mmol}$ of thionyl chloride $(\sim 0.5 \mathrm{~mL})$ were added. The mixture was then heated to $60{ }^{\circ} \mathrm{C}$ and stirred overnight. The solvent was evaporated, and the oily residue was taken up in $10 \mathrm{~mL}$ of ethyl acetate and washed twice with $10 \mathrm{~mL}$ of saturated aqueous $\mathrm{NaHCO}_{3}$, and $10 \mathrm{~mL}$ of brine. The organic phase was dried using anhydrous $\mathrm{Na}_{2} \mathrm{SO}_{4}$, and the solvent was evaporated. Methyl pyrazinoate (1), $80 \%$ yield. ${ }^{1} \mathrm{H}-\mathrm{NMR}\left(\mathrm{CDCl}_{3}, 300 \mathrm{MHz}\right.$, $\delta=$ ppm) $4.07(\mathrm{~s}, 3 \mathrm{H}), 8.75(\mathrm{dd}, J=2.4,1.4 \mathrm{~Hz}, 1 \mathrm{H}), 8.80$

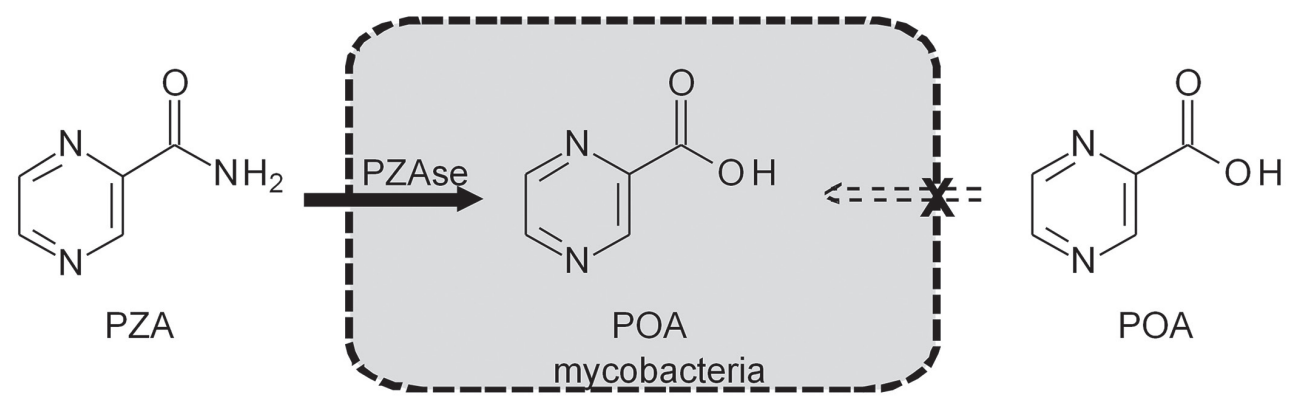

FIGURE 1 - Illustration of the mechanism of action of the pyrazinoic acid (POA) prodrugs, which POA itself cannot penetrate the mycobacterial membranes, whereas pyrazinamide (PZA) is activated to pyrazinoic acid (POA) inside mycobacteria. 
$(\mathrm{d}, J=2.4 \mathrm{~Hz}, 1 \mathrm{H}), 9.35(\mathrm{~d}, J=1.4 \mathrm{~Hz}, 1 \mathrm{H}) \cdot{ }^{13} \mathrm{C}-\mathrm{NMR}$ $\left(\mathrm{CDCl}_{3}, 75 \mathrm{MHz}, \delta=\right.$ ppm) $53.2,143.4,144.4,146.3,147.8$, 164.4. Ethyl pyrazinoate (2), $77 \%$ yield. ${ }^{1} \mathrm{H}-\mathrm{NMR}\left(\mathrm{CDCl}_{3}\right.$, $300 \mathrm{MHz}, \delta=\mathrm{ppm}) 1.47(\mathrm{t}, J=7.1 \mathrm{~Hz}, 3 \mathrm{H}), 4.53(\mathrm{q}, J=7.1$ $\mathrm{Hz}, 2 \mathrm{H}), 8.74$ (dd, $J=2.4,1.4 \mathrm{~Hz}, 1 \mathrm{H}), 8.78(\mathrm{~d}, J=2.4 \mathrm{~Hz}$, $1 \mathrm{H}), 9.33(\mathrm{~d}, J=1.4 \mathrm{~Hz}, 1 \mathrm{H}) .{ }^{13} \mathrm{C}-\mathrm{NMR}\left(\mathrm{CDCl}_{3}, 75 \mathrm{MHz}\right.$, $\delta=\mathrm{ppm}) 14.3,62.5,143.7,144.5,146.4,147.7,164.0$. Butyl pyrazinoate $(3), 60 \%$ yield. ${ }^{1} \mathrm{H}-\mathrm{NMR}(\mathrm{CDCl} 3,300 \mathrm{MHz}$, $\delta=\mathrm{ppm}) 0.99(\mathrm{t}, J=7.4 \mathrm{~Hz}, 3 \mathrm{H}), 1.49$ (sext, $J=7.4 \mathrm{~Hz}, 2 \mathrm{H})$, 1.83 (quint, $J=7.1 \mathrm{~Hz}, 2 \mathrm{H}), 8.75(\mathrm{dd}, J=2.4,1.4 \mathrm{~Hz}, 1 \mathrm{H})$, $8.78(\mathrm{~d}, J=2.4 \mathrm{~Hz}, 1 \mathrm{H}), 9.33(\mathrm{~d}, J=1.4 \mathrm{~Hz}, 1 \mathrm{H}) .{ }^{13} \mathrm{C}-\mathrm{NMR}$ $(\mathrm{CDCl} 3,75 \mathrm{MHz}, \delta=\mathrm{ppm}) 13.8,19.2,30.6,66.3,143.6$, 144.5, 146.3 147.6, 164.0. 2-Chloroethyl pyrazinoate (4), $85 \%$ yield. ${ }^{1} \mathrm{H}-\mathrm{NMR}\left(\mathrm{CDCl}_{3}, 300 \mathrm{MHz}, \delta=\mathrm{ppm}\right) 3.95(\mathrm{t}$, $J=5.6 \mathrm{~Hz}, 2 \mathrm{H}), 4.75(\mathrm{t}, J=5.6 \mathrm{~Hz}, 2 \mathrm{H}), 8.82(\mathrm{dd}, J=2.4$, $1.4 \mathrm{~Hz}, 1 \mathrm{H}), 8.87(\mathrm{~d}, J=2.4 \mathrm{~Hz}, 1 \mathrm{H}), 9.34(\mathrm{~d}, J=1.4 \mathrm{~Hz}$, $1 \mathrm{H}) .{ }^{13} \mathrm{C}-\mathrm{NMR}\left(\mathrm{CDCl}_{3}, 75 \mathrm{MHz}, \delta=\mathrm{ppm}\right) 41.2,65.5,143.1$, 144.6, 146.4, 148.0, 163.5.

\section{Preparation of the molecule 5}

In a round-bottom flask, $12 \mathrm{mmol}$ of POA (1.488 g) were dissolved in $10 \mathrm{~mL}$ of acetonitrile, when $5 \mathrm{mmol}$ of 1,2-dibromoethane $(0.940 \mathrm{~g})$ and $10 \mathrm{mmol}$ of triethylamine $(1.100 \mathrm{~g})$ were added. The reaction mixture was stirred under reflux for $12 \mathrm{~h}$, and the solvent was then evaporated. The residue was taken up in $10 \mathrm{~mL}$ of ethyl acetate, and washed twice with $10 \mathrm{~mL}$ of aqueous $\mathrm{NaHCO}_{3}$, and $10 \mathrm{~mL}$ of distilled water. The organic layer was dried using anhydrous $\mathrm{Na}_{2} \mathrm{SO}_{4}$, and the solvent was evaporated. The crude product was purified using flash column chromatography, using a hexane-ethyl acetate gradient as eluent. 2-(Pyrazinoyloxy)-ethyl pyrazinoate (5), 40\% yield. ${ }^{1} \mathrm{H}-\mathrm{NMR}\left(\mathrm{CDCl}_{3}, 300 \mathrm{MHz}, \delta=\mathrm{ppm}\right) 4.85(\mathrm{~s}, 4 \mathrm{H})$, $8.74(\mathrm{dd}, J=2.4,1.5 \mathrm{~Hz}, 2 \mathrm{H}), 8.78(\mathrm{~d}, J=2.4 \mathrm{~Hz}, 2 \mathrm{H}), 9.32$ $(\mathrm{d}, J=1.5 \mathrm{~Hz}, 2 \mathrm{H}) \cdot{ }^{13} \mathrm{C}-\mathrm{NMR}\left(\mathrm{CDCl}_{3}, 75 \mathrm{MHz}, \delta=\mathrm{ppm}\right)$ 63.6, 143.0, 144.5, 146.5, 148.0, 163.8 .

\section{Anti-Sporothrix spp. activity}

For in vitro tests, $S$. brasiliensis clinical isolates $(n=6)$ obtained from cats with sporotrichosis in Pelotas/ RS (codes S68, S120, S141, S144 and S146) and São Lourenço do Sul/RS (code S119), which both cities are located in southern Brazil, were used, as well as standard strains from human sporotrichosis by $S$. brasiliensis (Ss 177, also identified as IPEC 16919 from Instituto de Pesquisa Clínica Evandro Chagas, FIOCRUZ, Brazil) and $S$. schenckii sensu stricto (Ss 126), totaling eight fungal isolates. All isolates were molecularly identified at Laboratório de Micologia Médica Molecular (Federal
University of São Paulo, Brazil) by PCR-restriction fragment length polymorphism analysis (Rodrigues, de Hoog, de Camargo, 2014b). The in vitro antifungal test was performed using the broth microdilution method, according to the CLSI M38-A2 standard protocol (NCCLS, 2008).

The fungal inoculum was prepared from colonies grown in mycelial phase on potato-dextrose agar at $27^{\circ} \mathrm{C}$ for seven days. Saline solution $(2 \mathrm{~mL})$ with Tween $80(1 \%)$ was added to the surface of each colony and the fungal content was scraped with a scalpel blade to collect filament cells and conidia. The fungal content was transferred and suspended in tubes containing sterile saline, and adjusted to $1.0 \mathrm{McF}$ arland scale and, subsequently, in an ultraviolet (UV)-visible spectrophotometer (Spectrum Instruments Co.) with transmittance adjusted to $80-82 \%$ at the fixed wavelength of $530 \mathrm{~nm}$. Suspensions were diluted in RPMI1640 medium buffered with $2 \%$ glucose and MOPS at $1: 50, \mathrm{v} / \mathrm{v})$. The molecules were prepared in RPMI-1640 $(1.6 \mathrm{~mL})$ and DMSO $(0.05 \mathrm{~mL})$ to promote their dilution. From the initial concentration, ten serial dilutions were performed on RPMI-1640 medium buffered with MOPS directly on microplates to obtain a final concentration of $3.35-0.006 \mathrm{mg} / \mathrm{mL}$ (1); 3.06-0.006 mg/mL (2); 4.24$0.008 \mathrm{mg} / \mathrm{mL}(3) ; 5.15-0.01 \mathrm{mg} / \mathrm{mL}$ (4); $2.9-0.005 \mathrm{mg} /$ $\mathrm{mL}(\mathbf{5})$ and $3.18-0.006 \mathrm{mg} / \mathrm{mL}$ (POA).

Fungal suspension $(100 \mu \mathrm{l})$ was added in all tested wells, including in the positive control. Extract suspensions diluted in RPMI-1640 were used as negative control. Positive control consisted in RPMI-1640 with fungal suspension. For itraconazole preparation, the internal content was diluted using DMSO and prepared according to standards guidelines (NCCLS, 2008) to obtain a final concentration of 16 to $0.0313 \mu \mathrm{g} / \mathrm{mL}$. Microplates were incubated at $35^{\circ} \mathrm{C}$ for $72 \mathrm{~h}$ to obtain the results of minimum inhibitory concentration (MIC). For minimum fungicidal concentration (MFC), $10 \mu \mathrm{l}$ aliquots of the wells with no fungal growth were transferred to Petri dishes containing Sabouraud dextrose agar and incubated at $27^{\circ} \mathrm{C}$ for $72 \mathrm{~h}$ to visualize fungal growth. All experiments were performed in duplicate.

\section{LogP calculation}

The estimated $\log \mathrm{P}$ was calculated using the software Marvin version 14.8.11, using the calculation plugin implemented in the software. The calculation method is based on the publication of Viswanadhan et al. (1989), which is weighted by Klopman method and Physprop database data. Considered electrolyte concentrations $\left(\mathrm{Na}^{+}\right.$, $\mathrm{K}^{+}$and $\mathrm{Cl}^{-}$) were $0.1 \mathrm{~mol} / \mathrm{L}$. 


\section{Statistical analysis}

Analysis of variance and comparison of geometric means were performed by the Kruskal-Wallis test. Data were analyzed using the statistical software BioEstat ${ }^{\circledR}$ (version 5.3), and a $\mathrm{P}$ value of 0.05 was considered significant.

\section{RESULTS}

The five POA derivatives 1-5 (Figure 2) were prepared using the previously reported methodology from our group (Segretti et al., 2016), with moderate to good yields. The spectroscopic evaluation led to data in accordance with the literature.

As can be seen in Table I, a variable antifungal activity among the POA and their derivatives 1-5 is noted, which the parent drug POA presented only weak or no antiSporothrix spp. activity. However, the esterification of the carboxylic acid led to improved activity. In this way, the compounds 3 and $\mathbf{4}$ can be highlighted due to fungistatic and fungicidal activities against $100 \%$ of S. brasiliensis isolated from cats (6/6) and $S$. schenckii standard strain from a human. For compound $\mathbf{3}$, the antifungal activity values ranged from 2.12 to $1.06 \mathrm{mg} / \mathrm{mL}$ (MIC) and from 4.24 to $1.06 \mathrm{mg} / \mathrm{mL}$ (MFC), whereas for compound 4 ranged from 0.32 to $2.56 \mathrm{mg} / \mathrm{mL}$ (MIC) and from 1.29 to $5.15 \mathrm{mg} / \mathrm{mL}$ (MFC). However, one $S$. brasiliensis standard strain from human (Ss177) was not sensitive to none compound.

On the other hand, only $83.3 \%$ (5/6) of feline $S$. brasiliensis were sensitive to inhibitory activity of 2 (MIC from 3.06 to $0.77 \mathrm{mg} / \mathrm{mL}$ ) and 5 (MIC from 2.9 to 0.05 $\mathrm{mg} / \mathrm{mL}$ ), but a weak fungicidal activity was noted in only two feline isolates for both molecules, which the values of MFC on $50 \%$ and $90 \%$ of overall isolates $\left(\mathrm{MFC}_{50}\right.$ and $\mathrm{MFC}_{90}$, respectively) were $>3.06 \mathrm{mg} / \mathrm{mL}$ for 2 and $>2.90 \mathrm{mg} / \mathrm{mL}$ for $\mathbf{5}$. The remaining molecules were considered weakly active against $S$. brasiliensis $\left(\mathrm{MIC}_{50 \text { and }}\right.$ ${ }_{90}$ and $\mathrm{MFC}_{50 \text { and } 90}$ were $>3.34 \mathrm{mg} / \mathrm{mL}$ for molecule $\mathbf{1}$ and $>3.18 \mathrm{mg} / \mathrm{mL}$ for POA).

Molecules $\mathbf{3}$ and $\mathbf{4}$ were the only active molecules on the overall microorganisms since the values of $\mathrm{MIC}_{90}$ and $\mathrm{MFC}_{90}$ were $2.12 \mathrm{mg} / \mathrm{mL}$ and $4.24 \mathrm{mg} / \mathrm{mL}$ (for 3) and were $2.56 \mathrm{mg} / \mathrm{mL}$ and $5.15 \mathrm{mg} / \mathrm{mL}$ (for 4). The remaining molecules did not present this activity, showing values higher than the maximum concentration tested. Considering the overall Sporothrix spp. tested, 75\% $(6 / 8)$ were sensitive to the antifungal choice for therapy in human and animals, itraconazole (Table II). The cutoff point was followed according to document M38-A2 (NCCLS, 2008), in which fungal isolates with MIC values lower than or equal to $4 \mu \mathrm{g} / \mathrm{mL}$ are considered sensitive. On the other hand, two feline isolates showed MIC values ranging from 8 to $>16 \mu \mathrm{g} / \mathrm{mL}$ and were then considered itraconazole-resistant isolates.

\section{DISCUSSION}

POA is considered the active form of the tuberculostatic drug PZA, produced by PZA hydrolysis from a specific mycobacterial enzyme, PZAse (Zhang et al., 2003). PZA (and even POA) is especially active against the slow-growing intracellular M. tuberculosis, suggesting<smiles>O=C(O)c1cnccn1</smiles>

POA $\log \mathrm{P}-0.47$<smiles>COC(=O)c1cnccn1</smiles>

1 $\log P-0.27$<smiles>O=C(OCCCl)c1cnccn1</smiles><smiles>CCOC(=O)c1cnccn1</smiles>

2 $\log P 0.08$<smiles>O=C(OCCOC(=O)c1cnccn1)c1cnccn1</smiles>

5 $\log P-0.72$

FIGURE 2 - Chemical structure of the pyrazinoic acid (POA) and their derivatives 1-5 evaluated in this work, and respective experimental values of partition coefficient $(\log \mathrm{P})$ as quantitative measure of the lipophilicity. 
TABLE I - Minimal inhibitory concentration (MIC) and minimal fungicidal concentration (MFC) of different pyrazinoic acids (POA) molecules $(\mathrm{mg} / \mathrm{mL})$ to Sporothrix brasiliensis isolated from cats in Southern Brazil ${ }^{\mathrm{a}}$

\begin{tabular}{|c|c|c|c|c|c|c|c|c|c|c|c|c|c|}
\hline \multirow[t]{2}{*}{ Code $^{b}$} & \multirow{2}{*}{$\begin{array}{c}\text { Host } \\
\text { (Braz. State) }\end{array}$} & \multicolumn{2}{|c|}{1} & \multicolumn{2}{|c|}{2} & \multicolumn{2}{|c|}{3} & \multicolumn{2}{|c|}{4} & \multicolumn{2}{|c|}{5} & \multicolumn{2}{|c|}{ POA } \\
\hline & & MIC & MFC & MIC & MFC & MIC & MFC & MIC & MFC & MIC & MFC & MIC & MFC \\
\hline S68 & Feline (RS) & 0.83 & 0.83 & 0.77 & 0.77 & 1.06 & 2.12 & 1.29 & 1.29 & 0.73 & 0.73 & 1.59 & 3.18 \\
\hline S120 & Feline (RS) & n.i. & n.f. & n.i. & n.f. & 2.12 & 4.24 & 1.29 & 2.56 & n.i. & n.f. & n.i. & n.f. \\
\hline S141 & Feline (RS) & n.i. & n.f. & 3.06 & n.f. & 2.12 & 2.12 & 2.56 & 2.56 & 2.9 & n.f. & n.i. & n.f. \\
\hline S146 & Feline (RS) & 0.83 & 3.34 & 1.53 & n.f. & 2.12 & 2.12 & 1.29 & 2.56 & 2.9 & n.f. & n.i. & n.f. \\
\hline Ss $177^{c}$ & Human (RJ) & n.i. & n.f. & n.i. & n.f. & n.i. & n.f. & n.i. & n.f. & n.i. & n.f. & n.i. & n.f. \\
\hline$\underline{\mathrm{Ss} 126^{\mathrm{c}}}$ & Human (SP) & n.i. & n.f. & n.i. & n.f. & 2.12 & 4.24 & 2.56 & 5.15 & n.i. & n.f. & n.i. & n.f. \\
\hline \multirow[t]{2}{*}{ Overall $^{d}$} & $50 \%$ & n.i. & n.f. & 3.06 & n.f. & 2.12 & 2.12 & 1.29 & 2.56 & 2.9 & n.f. & n.i. & n.f. \\
\hline & $90 \%$ & n.i. & n.f. & n.i. & n.f. & 2.12 & 4.24 & 2.56 & 5.15 & n.i. & n.f. & n.i. & n.f. \\
\hline
\end{tabular}

${ }^{a}$ Concentration range tested: $3.35-0.006 \mathrm{mg} / \mathrm{mL}(\mathbf{1}-$ Methyl pyrazinoate $) ; 3.06-0.006 \mathrm{mg} / \mathrm{mL}(\mathbf{2}-$ Ethyl pyrazinoate); $4.24-0.008 \mathrm{mg} / \mathrm{mL}$ (3 - Butyl pyrazinoate); 5.15-0.01 mg/mL (4 - 2-Chloroethyl pirazynoate); 2.9-0.005 mg/mL (5 - 2(Pyrazinoyloxy)-ethyl pyrazinoate); $3.18-0.006 \mathrm{mg} / \mathrm{mL}$ (POA - Pyrazinoic acid); "S" strains are Sporothrix brasiliensis and belong to the culture collection of the Faculty of Veterinary, Federal University of Pelotas, UFPEL, RS, Brazil; " "Ss" strains belong to the culture collection of the Federal University of São Paulo (UNIFESP, SP, Brazil) - Ss177, Sporothrix brasiliensis standard strain (other codes: FMR 8314, Facultat de Medicina i Ciències de la Salut, Reus, Spain; IPEC 16968, Instituto de Pesquisa Evandro Chagas/FIOCRUZ, RJ, Brazil); Ss 126, Sporothrix schenckii standard strain; ${ }^{\mathrm{d}}$ $50 \%, \mathrm{MIC} / \mathrm{MFC}$ at which $50 \%$ of overall isolates were inhibited/killed; $90 \%$, MIC/MFC at which $90 \%$ of overall isolates were inhibited/killed. n.i.: no inhibitory activity at the concentrations tested; n.f.: no fungicidal activity at the concentrations tested.

TABLE II - Susceptibility of Sporothrix schenckii complex isolates to itraconazole $(\mu \mathrm{g} / \mathrm{mL})$

\begin{tabular}{|c|c|c|c|c|}
\hline \multirow[t]{2}{*}{ Sporothrix schenckii complex (n) } & \multirow[t]{2}{*}{ Host } & \multicolumn{3}{|c|}{ Itraconazole $(n)^{\mathrm{a}}$} \\
\hline & & Sensitive & Resistant & Total \\
\hline S. brasiliensis (6) b & Feline (RS/Brazil) & 4 & 2 & 6 \\
\hline S. schenckii (1) ${ }^{\mathrm{c}}$ & Human (SP/Brazil) & 1 & - & 1 \\
\hline Overall (8) & - & 6 & 2 & 8 \\
\hline
\end{tabular}

a Sensitivity (MIC $\leq 4 \mu \mathrm{g} / \mathrm{mL}$ ) and resistance (MIC $>4 \mu \mathrm{g} / \mathrm{mL}$ ) defined according to the cut-off suggested by the M38-A2 (NCCLS, 2008); ${ }^{b}$ Clinical isolates from feline sporotrichosis belong to the culture collection of the Faculty of Veterinary, Federal University of Pelotas, UFPEL, RS, Brazil; ' Standard strain from human sporotrichosis belong to the culture collection of the Federal University of São Paulo (UNIFESP, SP, Brazil) - Sporothrix brasiliensis (Ss177, other codes: FMR 8314, Facultat de Medicina i Ciències de la Salut, Reus, Spain; IPEC 16919, Instituto de Pesquisa Evandro Chagas/FIOCRUZ, RJ, Brazil); Sporothrix schenckii (Ss 126).

that its action depends on some characteristics present in this subpopulation (Segretti et al., 2016). Although POA is the responsible for most of the observed effects of PZA, it cannot pass the mycobacterial membranes and thus it only possesses weak or no antimycobacterial activity. To improve its efficacy independently from the PZAse activation step, POA esters have been prepared and evaluated as antimycobacterial agents, showing very improved efficacy than POA (Fernandes et al., 2014; Segretti et al., 2016). On the other hand, POA and its ester derivatives do not show considerable activity against other bacteria.
Considering that mycobacteria and fungi (Willcocks, Wren, 2014) present some similarities (such as slowgrowing, the capacity of synthesizing threalose and inositol), we raised one question: Can POA and its derivatives be active against fungi? To answer this question in this work and taking advantage of the repositioning strategy (Ashburn and Thor, 2004; Corsello et al., 2017), we decided to explore the antifungal potential of these compounds against Sporothrix spp. clinical isolates from humans and animals with sporotrichosis. Considering that PZA can interfere in enzymes present in Leishmania that 
have similar function than mycobacterial FASI (Mendez et al., 2009), by analogy it could also act in similar enzymes from fungi. To the best of our knowledge, this is the first report comprising the antifungal activity of POA and derivatives against this fungal microorganism.

The results showed that POA itself did not present important antifungal activity in the tested concentrations. This is probably due to a penetration issue through fungal cell membranes, which are considerably lipophilic. The ionization state of POA in the physiological $\mathrm{pH}$ difficult its penetration into the fungal cell, so the ester derivatives that do not ionize in this $\mathrm{pH}$ would improve the penetration and therefore the antifungal activity (Zhang et al., 2003; Fernandes et al., 2014). As can be noted in Table I, more lipophilic POA derivatives 1-4 have shown better antifungal activity. The more lipophilic (represented by $\log$ P values, Figure 2 ) the molecule, the higher antifungal activity. Compounds $3(\log \mathrm{P} 1.05)$ and $4(\log \mathrm{P} 0.39)$ showed the better anti-Sporothrix activity, exhibiting activity even in itraconazole-resistant isolates. The role of lipophilicity can be observed when comparing the activity of compounds 1 to 4 , being $3>4>2>1$.

Interestingly, compound $\mathbf{5}$ is the more hydrophilic compound $(\log \mathrm{P}-0.72)$ in the series, but it exhibited some anti-Sporothrix spp. activity. Compound $\mathbf{5}$ was designed as a double prodrug of POA, that after hydrolysis it will generate 2 moles-equivalent of POA instead of 1 . It is a strategy to increase the intracellular concentration of POA, duplicating its efficacy (Segretti et al., 2016). In counterpart, the presence of two POA moieties leads to increased hydrophilicity, which limits the penetration of $\mathbf{5}$ into the fungal cell. This can be the reason for the limited antifungal activity observed for this compound.

Although a more specific study must be done to determine the mechanism of POA derivatives' action in fungi, the results suggest that esterification is necessary to POA exert its action inside the fungal cell. Since POA itself also presented poor activity in Sporothrix brasiliensis as observed previously to mycobacteria (Fernandes et al., 2014; Segretti et al., 2016), it is possible that the esters must be hydrolyzed by cytoplasmic esterases, generating the active POA inside the fungal cell, in a similar way that was illustrated in Figure 1. However, it is also possible that the esters may exert fungistatic action per se, i.e. independently of the hydrolysis step.

Regarding the S. brasiliensis tested, the S68 and S119 isolates were sensitive to POA derivatives 1-5; S141 and S144 were sensitive to 3 and 4 and both were inhibited by $\mathbf{2}$ and $\mathbf{5}$. In standards strains, $S$. schenckii (Ss126) was only sensitive to $\mathbf{3}$ and $\mathbf{4}$, and $S$. brasiliensis (Ss177) was not sensitive to any compounds tested. Although all these cited Sporothrix species were itraconazole-susceptible isolates, a difference in the profile of antifungal susceptibility was observed and probably is due to the virulence factors related to them, like melanin (Mario et al., 2016), and other factors still poorly understood. On the other hand, the itraconazoleresistant isolates recognized in S120 and S146 were sensitive to 3 and $\mathbf{4}$, but only S146 was sensitive to $\mathbf{1}$ and was inhibited to $\mathbf{2}$ and $\mathbf{5}$. The ability to resist to the action of itraconazole was also showed in $S$. brasiliensis isolated from feline and canine sporotrichosis (Waller et al., 2017), as well as in other Sporothrix species, such as $S$. albicans and $S$. luriei from feline and canine cases, respectively (Oliveira et al., 2011) and S. globosa from human sporotrichosis (Fischman Gompertz et al., 2016). In our study, the activity profile of POA derivatives in two itraconazole-resistant isolates (S120 and S146) shed light on the activity of these molecules. These isolates were only sensitive to inhibitory and fungicidal activities of 3 (MIC/MFC values 2.12-4.24 mg/mL) and 4 (MIC/ MFC values $1.29-2.56 \mathrm{mg} / \mathrm{mL}$ ) molecules, indicating a probable alternative route of these compounds from the mechanism of action of itraconazole.

The main mode of action of itraconazole is the inhibition of lanosterol $14-\alpha$-demethylase (Kelly et al., 1995 ) that is a key enzyme from the cytochrome P450 family in the ergosterol biosynthesis (Borgers, Van de Ven, 1989). Ergosterol is a membrane sterol important for fungal integrity and maintenance. As consequence, the inhibition of this enzyme leads to the inhibition of the fungal growth. The inhibition of ergosterol biosynthesis together with the increased permeability of the fungal cell membrane by ergosterol deficiency, lead to morphological changes like abnormalities at the plasma membrane, the cell wall and cytoplasmic vacuoles, with defective cell division, abortive hyphal outgrowth and loss of cell viability (Borgers, Van de Ven, 1989). The activity of compounds 1-5 seems to be independent of lanosterol 14- $\alpha$-demethylase inhibition since their action occurs independently of the resistance. Maybe a similar role played in M. tuberculosis and L. major may be involved in this effect, however the mechanism of action for POA derivatives is still unknown.

This study demonstrates the potential of pyrazinoic acid and their derivatives as antifungal, which the most lipophilic molecules were active, including against itraconazole-resistant $S$. brasiliensis. The findings support potential usefulness of these molecules in the treatment of sporotrichosis and further studies should be undertaken to understand their mechanism of action and to evaluate their safe use. 


\section{ACKNOWLEDGMENTS}

The authors are thankful to Zoilo Pires de Camargo (Universidade Federal de São Paulo - UNIFESP, São Paulo/SP, Brazil) for the biomolecular analysis of the fungal isolates.

\section{CONFLICT OF INTEREST}

The authors declare that there are no conflicts of interest regarding this manuscript.

\section{REFERENCES}

Ashburn TT, Thor KB. Drug repositioning: Identifying and developing new uses for existing drugs. Nat Rev Drug Discov. 2004;3(8): 673-83.

Borba-Santos LP, Rodrigues AM, Gagini TB, Fernandes GF, Castro R, de Camargo, et al. Susceptibility of Sporothrix brasiliensis isolates to amphotericin $\mathrm{B}$, azoles, and terbinafine. Med Mycol. 2015;53(2):178-88.

Borgers M, Van de Ven MA. Mode of action of itraconazole: morphological aspects. Mycoses. 1989;32(1):53-9.

Corsello SM, Bittker JA, Liu Z, Gould J, McCarren P, Hirschman JE, et al. The drug repurposing hub: A next generation drug library and information resource. Nat Med. 2017;23(4):405-8.

De Araújo ML, Rodrigues AM, Fernandes GF, de Camargo ZP, de Hoog GS. Human sporotrichosis beyond the epidemic front reveals classical transmission types in Espírito Santo, Brazil. Mycoses. 2015;58(8):485-90.

Fernandes JPS, Pavan FR, Leite CQ, Felli VM. Synthesis and evaluation of a pyrazinoic acid prodrug in Mycobacterium tuberculosis. Saudi Pharm J. 2014;22(4):376-80.

Fischman Gompertz O, Rodrigues AM, Fernandes GF, Bentubo HD, de Camargo ZP, petri V. Atypical clinical presentation of sporotrichosis caused by Sporothrix globosa resistant to itraconazole. Am J Trop Med Hyg. 2016;94(6):1218-22.

Kelly SL, Lamb DC, Corran AJ, Baldwin BC, Kelly De. Mode of action and resistance to azole antifungals associated with the formation of $14 \alpha$-methylergosta-8,24(28)-dien-3 $\beta, 6 \alpha$-diol. Biochem Biophys Res Commun. 1995;207(3):910-5.
Madrid IM, Mattei AS, Fernandes CG, Nobre MO, Meireles MC. Epidemiological findings and laboratory evaluation of sporotrichosis: a description of 103 cases in cats and dogs in Southern Brazil. Mycopathologia. 2012;173(4):265-73.

Marimon R, Cano J, Gené J, Sutton DA, Kawasaki M, Guarro J. Sporothrix brasiliensis, S. globosa and S. mexicana, three new Sporothrix species of clinical interest. [J Clin Microbiol. 2007;45(10):3198-206.

Mario DA, Santos RC, Denardi LB, Vaucher RdeA, Santurio $\mathrm{JM}$, Alves SH. Interference of melanin in the susceptibility profile of Sporothrix species to amphotericin B. Rev Iberoam Micol. 2016;33(1):21-5.

Mendez S, Traslavina R, Hinchman M, Huang L, Green P, Cynamon $\mathrm{MH}$, et al. The antituberculosis drug pyrazinamide affects the course of cutaneous leishmaniasis in vivo and increases activation of macrophages and dendritic cells. Antimicrob Agents Chemother. 2009;53(12):5114-21.

Montenegro H, Rodrigues AM, Dias MA, da Silva EA, Bernardi F, de Camargo ZP. Feline sporotrichosis due to Sporothrix brasiliensis: an emerging animal infection in São Paulo, Brazil. BMC Vet Res. 2014;10:269.

NCCLS - Clinical and Laboratory Standards Institute. Reference Method for Broth Dilution Antifungal Susceptibility Testing of Filamentous Fungi: approved standard M38-A of NCCLS, 2nd edn. Wayne, Pennsylvania; 2008.

Oliveira DC, Lopes PG, Spader TB, Mahl CD, Tronco-Alves GR, Lara VM, et al. Antifungal susceptibilities of Sporothrix albicans, S. brasiliensis, and S. luriei of the S. schenckii complex identified in Brazil. J Clin Microbiol. 2011;49(8):3047-9.

Rodrigues AM, de Hoog GS, Pires DC, Brilhante RSN, Sidrim JJC, Gadelha AL, et al. Genetic diversity and antifungal susceptibility profiles in causative agents of sporotrichosis. BMC Infect Dis. 2014a;14:219.

Rodrigues AM, de Hoog GS, de Camargo ZP. Genotyping species of the Sporothrix schenckii complex by PCR-RFLP of calmodulin. Diagn Microbiol Infect Dis. 2014b;78(4):383-7.

Segretti ND, Simões CK, Corrêa MF, Felli VM, Miyata M, Cho $\mathrm{SH}$, et al. Antimycobacterial activity of pyrazinoate prodrugs in replicating and non-replicating Mycobacterium tuberculosis. Tuberculosis (Edinb). 2016;99:11-6. 
Viswanadhan VN, Ghose AK, Revankar GR, Ronins RK. Atomic physicochemical parameters for three dimensional structure directed quantitative structure-activity relationships. 4. Additional parameters for hydrophobic and dispersive interactions and their application for an automated superposition of certain naturally occurring nucleoside antibiotics. J Chem Inf Comput Sci. 1989;29(3):163-72.

Waller SB, Madrid IM, Silva AL, Dias de Castro LL, Cleff MB, Ferraz V, et al. In vitro susceptibility of Sporothrix brasiliensis to essential oils of Lamiaceae family. Mycopathologia, 2016;181(11-12):857-63.

Waller SB, Peter CM, Hoffmann JF, Picoli T, Osório LD, Chaves F, Zani JL, de Faria RO, de Mello JR, Meireles MC. Chemical and cytotoxic analyses of brown Brazilian propolis (Apis mellifera) and its in vitro activity against itraconazole-resistant Sporothrix brasiliensis. Microb Pathog. 2017;105:117-21.
Willcocks S, Wren BW. Shared characteristics between Mycobacterium tuberculosis and fungi contribute to virulence. Future Microbiol. 2014;9(5):657-68.

Zhang Y, Wade MM, Scorpio A, Zhang H, Sun Z. Mode of action of pyrazinamide: disruption of Mycobacterium tuberculosis membrane transport and energetics by pyrazinoic acid. J Antimicrob Chemother. 2003;52(5):790-5.

Zimhony O, Cox JS, Welch JT, Vilchèze C, Jacobs WR Jr. Pyrazinamide inhibits the eukaryotic-like fatty acid synthetase I (FASI) of Mycobacterium tuberculosis. Nat Med. 2000;6(9):1043-7.

Received for publication on $15^{\text {th }}$ January 2018 Accepted for publication on $12^{\text {th }}$ December 2018 